\title{
A Recent Argument for the Use of Endoscopic Submucosal Dissection for Early Gastric Cancers
}

\author{
Waku Hatta ${ }^{1}$, Takuji Gotoda ${ }^{2}$, Tomoyuki Koike ${ }^{1}$, and Atsushi Masamune ${ }^{1}$ \\ ${ }^{1}$ Division of Gastroenterology, Tohoku University Graduate School of Medicine, Sendai, and ${ }^{2}$ Division of Gastroenterology and Hepatology, \\ Department of Medicine, Nihon University School of Medicine, Tokyo, Japan
}

Endoscopic submucosal dissection (ESD) has become the standard treatment method for early gastric cancers (EGCS) due to the negligible risk for lymph node metastasis (LNM) in Eastern Asian countries. According to the guidelines, the curability of EGC after endoscopic resection was classified into three groups: curative resection, expanded curative resection, and noncurative resection. In Eastern Asian countries, a structured follow-up schedule is needed for patients undergoing curative resection and expanded curative resection. Conversely, in Western countries, additional surgery may be recommended for some patients undergoing expanded curative resection (ulcerated, undifferentiated, or slight submucosal invasion) due to the potential risk for LNM, even though specimens of ESD and surgery may not be handled with the same methodology as that used in Japan, which may lead to this slightly higher risk. In noncurative resection, additional surgery is the standard method after ESD because of the risk for LNM. However, in elderly patients and/or those with severe underlying diseases, the advantages and disadvantages of additional surgery should be considered when selecting a post-ESD treatment strategy for patients undergoing noncurative resection. Risk-scoring systems for LNM may facilitate clinical decisions for these patients. However, it should be noted that when recurrence was detected in patients who were followed up with no additional treatment after ESD with noncurative resection, most of them had a poor prognosis. To select an appropriate treatment method, especially in elderly patients undergoing ESD with noncurative resection, a new tool for evaluating the condition of patients should be established. (Gut Liver 2020;14:412-422)
Key Words: Endoscopic submucosal dissection; Neoplasms; Endoscopy; Stomach; Lymph nodes

\section{INTRODUCTION}

Gastric cancer is the fifth commonest cancer and the third leading cause of cancer-related death in the world. ${ }^{1}$ About 75\% of the cases appear in Asia, particularly in Korea, China, and Japan. ${ }^{2,3}$ For several decades, these Eastern Asian countries have made efforts to overcome gastric cancer. To reduce morbidity, Helicobacter pylori eradication is now widely conducted. In Japan, potassium-competitive acid blocker-containing triple therapy showed high efficacy for the eradication compared to proton pump inhibitor-containing therapy. ${ }^{4,5}$ Furthermore, its decreasing infection rate in the younger generation will lead to the lower prevalence of gastric cancer in the future. ${ }^{6,7}$ To reduce gastric cancer-related mortality, several screening methods for early detection, such as X-ray, endoscopy, and the combination of $H$. pylori antibody and pepsinogen I and II, are performed..$^{8-10}$ Recently in Japan, over half of gastric cancers were detected as early gastric cancers (EGCs), ${ }^{11}$ which are defined as a malignant lesion of the stomach that is confined to the mucosa or submucosa layer, regardless of the lymph node metastasis (LNM) status. ${ }^{12}$ In Korea, the rate of detection in the early stage of gastric cancer has increased up to $70 \% .^{13,14}$

Endoscopic resection (ER) is divided into endoscopic mucosal resection (EMR) and endoscopic submucosal dissection (ESD). EMR is widely accepted as a minimally invasive treatment method for EGCs with a negligible risk of LNM, ${ }^{11,15-18}$ and it provides a better quality of life. ESD has become the standard endoscopic technique as it allows en bloc resection of lesions ir-

\footnotetext{
Correspondence to: Takuji Gotoda ${ }^{\mathrm{a}}$ and Waku Hatta ${ }^{\mathrm{b}}$

${ }^{a}$ Division of Gastroenterology and Hepatology, Department of Medicine, Nihon University School of Medicine, 1-6 Kanda-Surugadai, Chiyoda-ku, Tokyo 101-8309, Japan

Tel: +81-3-3292-2880, Fax: +81-3-3293-1711, E-mail: takujigotoda@yahoo.co.jp

${ }^{b}$ Division of Gastroenterology, Tohoku University Graduate School of Medicine, 1-1 Seiryo-machi, Aoba-ku, Sendai 9808574, Japan

Tel: +81-22-717-7171, Fax: +81-22-717-7177, E-mail: waku-style@ festa.ocn.ne.jp

Received on June 3, 2019. Revised on July 27, 2019. Accepted on August 4, 2019. Published online September 30, 2019. pISSN 1976-2283 eISSN 2005-1212 https://doi.org/10.5009/gnl19194

(a) This is an Open Access article distributed under the terms of the Creative Commons Attribution Non-Commercial License (http://creativecommons.org/licenses/by-nc/4.0) which permits unrestricted non-commercial use, distribution, and reproduction in any medium, provided the original work is properly cited.
} 
respective of size and thereby permitting precise histopathological assessment of the resected specimen. ${ }^{19-23}$ ESD has become the standard method, instead of EMR, in Eastern Asian countries. In fact, over 90\% of ER for EGCs is ESD in Japan. ${ }^{24}$ Given its potential advantages over EMR, this procedure has begun to gain traction in some Western countries as well. ${ }^{25}$

With the development of the ESD technique since the first English report in 1999, ${ }^{26}$ the indication of ER for EGCs has expanded. Moreover, recent reports revealed the long-term outcome and the risk of gastric cancer-related mortality for each curability criterion in the guidelines. This review focuses on upto-date information about gastric ESD, particularly in EGCs that do not meet the curability criteria for ER.

\section{CURABILITY IN THE GUIDELINES}

The curability criteria for ER of EGCs have been defined in the European, Korean, and Japanese guidelines. ${ }^{25,27-29}$ Based on the risk of LNM, the guidelines classified the curability after ER for EGCs into three groups: curative resection for tumors of absolute indication, curative resection for tumors of expanded indication, and noncurative resection (Table 1). ${ }^{25,27-29}$ En bloc resection with no lymphovascular invasion and negative resection margins are required for curative resection or expanded curative resection. Additionally, curative resection is appropriate for differentiated, intramucosal cancer measuring $\leq 2 \mathrm{~cm}$ in diameter without ulceration. It is regarded as an expanded curative resection when the lesion is (1) differentiated, intramucosal cancer measuring $>2 \mathrm{~cm}$ in diameter and without ulceration; (2) differentiated, mucosal cancer measuring $\leq 3 \mathrm{~cm}$ with ulceration; (3) undifferentiated, mucosal cancer measuring $\leq 2 \mathrm{~cm}$ without ulceration; (4) differentiated cancer measuring $\leq 3 \mathrm{~cm}$ with a submucosal invasion depth of $<500 \mu \mathrm{m}$ (pT1b(SM1)). Undifferentiated cancer includes poorly-differentiated adenocarcinoma or signet ring cell carcinoma. Recently, the Japanese guidelines were updated, ${ }^{30}$ but are now available only in Japanese. In the guidelines, curability was divided into A (curative resection), $\mathrm{B}$ (expanded curative resection), and $\mathrm{C}$ (noncurative resection) (Table 2). ${ }^{30}$ Based on the favorable results in a multicenter prospective study, ${ }^{31}$ (1) and (2) of the criteria in expanded curative resection were regarded as curability $\mathrm{A}$ in the latest guidelines (Table 2). ${ }^{30}$ Curability C was subdivided into curability C-1 and C-2: curability C-1 corresponds to noncurative resection with a merely positive horizontal margin or piecemeal resection, and curability C-2 corresponds to the others. In addition, since differentiated EGC with a minor undifferentiated component in the submucosa has risk of $\mathrm{LNM}^{32}$ this was regarded as curability $\mathrm{C}-2$ in the latest guidelines. ${ }^{30}$

\section{CURATIVE RESECTION AND EXPANDED CURATIVE RESECTION}

\section{Risk of LNM}

The criteria of curative resection and expanded curative resection are mainly based on the reports by Gotoda et al..$^{33}$ and Hirasawa et al. $^{34}$ These reports analyzed a large series of EGCs and did not find any LNMs when EGCs meet the criteria for curative resection and expanded curative resection. ${ }^{33,34}$ However one of the major problems in this field is that most studies are from Korea and Japan. In fact, all of the included studies in a meta-analysis of LNM in the absolute and expanded criteria for ER were from Eastern Asian countries. ${ }^{35}$ Therefore, it is unclear whether these data can be extrapolated to the other countries. Recently, some studies have been reported from Western countries. In the national database of the United States, the rate of LNM in EGCs was $7.8 \%,{ }^{36}$ which is higher than the LNM rates in large Asian series (2\% to $5 \%$ ). ${ }^{33,37,38}$ In addition, the rates of LNM for white (9.6\%) and black (10.9\%) patients in mucosal gastric cancers were almost double that of Asian/Pacific islanders (5.2\%). ${ }^{36}$ The authors in this study suggested the existence of different biological aggressiveness in EGCs among racial/ethnic groups. A recent multicenter study in the United States includ-

Table 1. The Curability Criteria for ER of EGCs in the Japanese Guidelines (4th Version) 28,* $^{20}$

\begin{tabular}{|c|c|c|c|c|c|}
\hline \multirow[b]{2}{*}{ pT1a } & \multirow{2}{*}{$\begin{array}{c}\text { Ulceration } \\
\text { Negative }\end{array}$} & \multicolumn{2}{|c|}{ Differentiated-type } & \multicolumn{2}{|c|}{ Undifferentiated-type } \\
\hline & & $\leq 2 \mathrm{~cm}^{\dagger}$ & $>2 \mathrm{~cm}^{\dagger}$ & $\leq 2 \mathrm{~cm}^{\dagger}$ & $>2 \mathrm{~cm}$ \\
\hline & Positive & $\leq 3 \mathrm{~cm}^{\dagger}$ & $>3 \mathrm{~cm}$ & & \\
\hline pT1b(SM1) & & $\leq 3 \mathrm{~cm}^{\dagger}$ & $>3 \mathrm{~cm}$ & & \\
\hline
\end{tabular}

pT1b(SM2)

ER, endoscopic resection; EGCs, early gastric cancers; pT1b(SM1), a submucosal invasion depth of $<500 \mu \mathrm{m}$; pT1b(SM2), tumor invasion into the submucosa $\geq 500 \mu \mathrm{m}$ from the muscularis mucosa.

*White, gray, and black areas correspond to curative resection ${ }^{\dagger}$, expanded curative resection ${ }^{\dagger}$, and noncurative resection, respectively; ${ }^{\dagger}$ Piecemeal resection or positive horizontal margin is regarded as noncurative resection. 
Table 2. The Curability Criteria for ER of EGCs in the Latest Version of Japanese Guidelines (Currently Available Only in Japanese) (3)* $^{3}$

\begin{tabular}{|c|c|c|c|c|}
\hline \multirow{3}{*}{ pT1a } & \multirow{2}{*}{$\begin{array}{c}\text { Ulceration } \\
\text { Negative }\end{array}$} & \multicolumn{2}{|c|}{ Differentiated-type } & Undifferentiated-type \\
\hline & & $\leq 2 \mathrm{~cm}^{\dagger}$ & $>2 \mathrm{~cm}^{\dagger}$ & $\leq 2 \mathrm{~cm}^{\dagger}$ \\
\hline & Positive & $\leq 3 \mathrm{~cm}^{\dagger}$ & $>3 \mathrm{~cm}^{\dagger}$ & \\
\hline pT1b(SM1) & & $\leq 3 \mathrm{~cm}^{\dagger, \ddagger}$ & $>3 \mathrm{~cm}$ & \\
\hline
\end{tabular}

ER, endoscopic resection; EGCs, early gastric cancers; pT1b(SM1), submucosal invasion depth of $<500 \mu \mathrm{m}$; pT1b(SM2), tumor invasion into the submucosa $\geq 500 \mu \mathrm{m}$ from the muscularis mucosa.

*White, gray, and black areas correspond to curability $\mathrm{A}^{\dagger}$, curability $\mathrm{B}^{\dagger}$, and curability C-2, respectively; ${ }^{\dagger}$ Piecemeal resection or positive horizontal margins is regarded as curability $\mathrm{C}-1 ;{ }^{\ddagger} \mathrm{A}$ lesion with a submucosal undifferentiated component is regarded as curability $\mathrm{C}-2$.

ing 176 patients with EGC also found a higher rate of LNM in EGCs; 0\% (0/10) and 7.5\% (3/40) in patients fulfilling the absolute and expanded curative resection criteria for ER, respectively. ${ }^{39}$ However, differentiated and non-ulcerated intramucosal lesions $>2 \mathrm{~cm}$ in diameter had no LNM. Thus, in Western countries, EGCs that meet the criteria for curative resection may have negligible risk for LNM. Among EGCs that meet the criteria for expanded curative resection, differentiated and non-ulcerated intramucosal gastric cancers $>2 \mathrm{~cm}$ in diameter may have little risk for LNM. On the other hand, EGCs with the other type of expanded curative resection may have a certain degree of risk for LNM in Western countries. The discrepancy between Eastern Asian and Western countries may be partly due to a difference in biological aggressiveness. However, in Western countries, specimens of ESD and surgery may not be handled with the same methodology as in Japan, suggesting that a slightly higher risk of LNM might be expected in these countries. ${ }^{40}$ In the Japanese guidelines, ${ }^{12}$ the tissue slice preparation is recommended to be $2 \mathrm{~mm}$ for ER and 5 to $7 \mathrm{~mm}$ for surgical resection. For evaluating the difference in LNM between Eastern Asian and Western countries appropriately, the standardization of specimen handling and histological evaluation will be necessary.

\section{Long-term outcome and recurrence}

In this review, recurrence is defined as tumor relapse in the lymph nodes and/or other organs after ER for EGCs. Many studies revealed a favorable long-term outcome in patients with curative resection and expanded curative resection. ${ }^{41-47}$ A prospective multicenter cohort study from Korea revealed no gastric cancer-related mortality in 600 patients with curative resection and expanded curative resection of ESD during the follow-up duration. ${ }^{48}$ Concerning differentiated-type intramucosal gastric cancers that meet an expanded indication of ER, a prospective multicenter cohort study from Japan revealed that the 5-year overall survival (OS) was $97.0 \%$ and that no recurrence was observed in patients who satisfied the curative resection crite- ria. ${ }^{31}$ A prospective confirmatory trial for patients with ESD for undifferentiated-type EGCs that meet the expanded indication of ER also showed an excellent 5-year OS of 99.3\%. ${ }^{49}$ In a largescale multicenter retrospective study from Japan, recurrence was observed in $0 \%(0 / 6,456)$ and $0.14 \%(6 / 4,202)$ of patients with curative resection and expanded curative resection, respectively. ${ }^{50}$ Among cases with recurrence, pT1b(SM1), ulceration, and differentiated-predominant mixed histology were shown in three, three and three cases, respectively. ${ }^{50}$ A Korean large-scale single center study also showed that $0.14 \%(5 / 3,588)$ of patients with curative resection and expanded curative resection underwent recurrence after ESD. ${ }^{51}$ Another study from Korea reported $0.15 \%(2 / 1,306)$ of recurrence after curative resection and expanded curative resection. ${ }^{52}$ In these studies, most patients with curative resection and expanded curative resection have favorable long-term outcomes after ESD for EGC; however, it should be noted that a very small number of patients with expanded curative resection have recurrence.

In Western countries, a recent report from Germany recommended ESD for differentiated and non-ulcerated intramucosa lesions, due to the favorable long-term outcomes. ${ }^{53}$ However, data are lacking in the other type of expanded indication for ESD of EGC.

\section{Management after ESD}

Based on the reports about LNM in surgery and long-term outcome in ESD, the management after ESD should be different between Eastern Asian and Western countries. In Eastern Asian countries, patients with curative resection and expanded curative resection can be managed according to the Japanese guidelines, that is, endoscopic surveillance at intervals of 6 to 12 months for curative resection and endoscopic surveillance by endoscopy and computed tomography (CT) at intervals of 6 to 12 months for expanded curative resection (Fig. 1). ${ }^{27,28,30}$

In Western countries, patients with curative resection can be managed in the same way as in Eastern Asian countries. In 

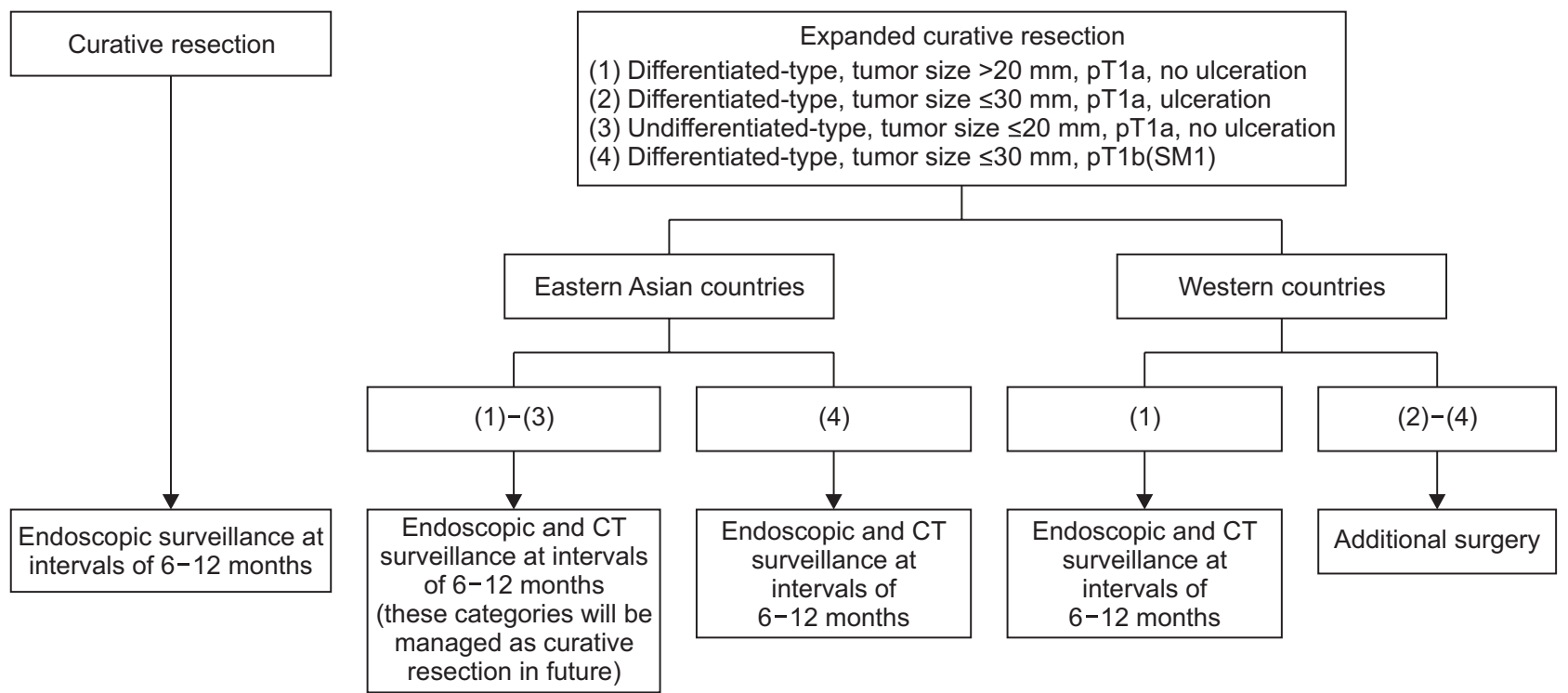

Fig. 1. Proposal for the management of patients undergoing endoscopic submucosal dissection with curative resection and expanded curative resection for early gastric cancers.

pT1b(SM1), tumor invasion into the submucosa $<500 \mu \mathrm{m}$ from the muscularis mucosa; CT, computed tomography.

Table 3. Long-Term Outcome of Patients Undergoing Noncurative ER for EGCs ( $\geq 100$ Cases)

\begin{tabular}{|c|c|c|c|c|c|c|c|c|}
\hline \multirow{2}{*}{ Author (year) } & \multirow{2}{*}{ Country } & \multirow{2}{*}{$\begin{array}{l}\text { No. of } \\
\text { patients }\end{array}$} & \multirow{2}{*}{$\begin{array}{l}\text { No additional } \\
\text { treatment, \% }\end{array}$} & \multirow{2}{*}{$\begin{array}{l}\text { Median follow-up } \\
\text { period, mo }\end{array}$} & \multicolumn{2}{|c|}{ Additional surgery, \% } & \multicolumn{2}{|c|}{ No additional treatment, \% } \\
\hline & & & & & $5-y r$ OS & 5-yr DSS & $5-y r$ OS & 5-yr DSS \\
\hline Hatta et al. $(2017)^{55}$ & Japan & 1,969 & 45.5 & 66 & 92.6 & 98.8 & 75.2 & 97.5 \\
\hline Suzuki et al. $(2017)^{57}$ & Japan & 540 & 35.6 & $76^{*}, 70^{\dagger}$ & 94.7 & 98.8 & 83.8 & 96.8 \\
\hline Kawata et al. (2017) ${ }^{58}$ & Japan & 506 & 36.2 & $65^{*}, 61^{\dagger}$ & 90.0 & 98.7 & 72.0 & 96.5 \\
\hline Kim et al. $(2015)^{60}$ & Korea & 274 & 29.2 & 60.5 & 94.3 & $99.5^{\ddagger}$ & 85.0 & $97.0^{\ddagger}$ \\
\hline Yang et al. $(2015)^{56}$ & Korea & 267 & 53.9 & 40.7 & NA & 98.7 & NA & 97.4 \\
\hline Yano et al. (2018) ${ }^{61}$ & Japan & 231 & 48.9 & 48 & 96.0 & 100 & 73.3 & 92.6 \\
\hline Kikuchi et al. $(2017)^{59}$ & Japan & 150 & 51.3 & $4.8 \mathrm{yr}^{*}, 4.7 \mathrm{yr}^{\dagger}$ & 85.0 & $97.0^{\S}$ & 79.4 & $95.3^{\S}$ \\
\hline
\end{tabular}

ER, endoscopic resection; EGC, early gastric cancers; OS, overall survival; DSS, disease-specific survival; NA, no assessment.

*In patients with additional surgery after endoscopic submucosal dissection (ESD) with noncurative resection; ${ }^{\dagger}$ In patients with no additional treatment after ESD with noncurative resection; ${ }^{ \pm}$Total survival rate; ${ }^{5}$ Recurrence-free survival.

expanded curative resection, differentiated and non-ulcerated intramucosal gastric cancer $>2 \mathrm{~cm}$ in diameter can be managed by endoscopic and CT surveillance, which is the same as in Eastern Asian countries. However, lesions with the other type of expanded curative resection might be regarded as noncurative resection that requires additional surgery, due to the potential risk of LNM (Fig. 1). ${ }^{39}$

\section{NONCURATIVE RESECTION}

\section{Long-term outcome in two treatment strategies after noncurative resection}

According to the guidelines, ${ }^{25,27-30}$ additional surgery is the standard therapy for patients with noncurative resection after ER. However, according to two large-scale studies, ${ }^{54,55}$ about half of such patients select follow-up with no additional treat- ment after ESD. Many studies have evaluated the long-term outcomes of two treatment methods after noncurative resection of ER (Table 3). ${ }^{55-61}$ All studies showed that the OS in patients with no additional treatment (72.0\% to $85.0 \%$ ) was lower than that in patients with additional surgery (85.0\% to $96.0 \%)^{55,57-61}$ However, this difference may be largely affected by a selection bias in the treatment strategy after ER because there is a discrepancy in the OS and disease-specific survival (DSS) between no additional treatment and additional surgery groups. In fact, the 5-year DSSs in patients with additional treatment and those with no additional treatment were $98.7 \%$ to $100 \%$ and $92.6 \%$ to $97.5 \%$, respectively. ${ }^{55-58,61}$ However, this is also affected by a selection bias in the treatment method after ER. According to a study using propensity-score matching analysis of the baseline characteristics for reducing this bias, additional surgery reduced cancer-specific mortality to one-third. ${ }^{62}$ 


\section{LNM in patients with additional surgery after noncurative resection}

The rate of LNM in patients who underwent additional surgery after noncurative resection of ER for EGC is reported to be 5.2\% to $11.0 \% .^{53,54,57-61,63-70}$ Most reports are from Korea and Japan, and only one study has been reported from Western countries. ${ }^{53}$ In this study, LNM after noncurative resection was shown in $8.3 \%$ of the patients $(1 / 12),{ }^{53}$ which is similar to the rate of LNM (8.5\%) in the largest study from Japan. ${ }^{64}$ However, it is difficult to detect LNM by preoperative CT. Actually, preoperative CT was not able to detect LNM in $90 \%$ of patients with LNM. $^{58}$

Many studies reported the risk factors for LNM after noncurative resection of ER (Table 4). ${ }^{57-59,63,64,66,67,69,70}$ In all studies evaluating the variable of lymphovascular invasion, this variable was a significant risk factor for LNM after ER with noncurative resection. In two studies that analyzed lymphatic and vascular invasions, separately, ${ }^{64,66}$ lymphatic invasion was the most important risk factor for LNM. Until now, tumor size $>30 \mathrm{~mm}$, tumor invasion into the submucosa $\geq 500 \mu \mathrm{m}$ from the muscularis mucosa (pT1b(SM2)), vascular invasion, positive vertical margin (VM), and macroscopic appearance of flat/elevated has been also reported as independent risk factors for LNM.

The undifferentiated-type of cancer was not a significant risk factor for LNM in all but one study (Table 4). However, a largescale study about additional surgery for EGC with pT1b(SM2) after ESD clarified that an undifferentiated component in submucosal invasion was an independent risk factor for LNM, despite the fact that the undifferentiated-type was not a risk factor. $^{71}$ Therefore, among undifferentiated-type EGC, a submucosal undifferentiated component may be important for LNM after ESD with noncurative resection. However, the results on the LNM rate in patients undergoing additional surgery after noncurative ER for undifferentiated-type EGC are different from the studies about gastrectomy as the initial treatment for EGC, which showed this as a risk factor for LNM. ${ }^{33}$ This discrepancy may be affected by a bias that arises from the initial treatment selection for EGC: surgical selection or ER. In fact, patients with undifferentiated-type EGC comprised $12.7 \%$ to $33.3 \%$ of the patients, , $^{57-59,63,64,66,67,69,70}$ which is lower than the prevalence of undifferentiated-type EGC reported in previous studies of surgery for EGC (35.9\% to 40.4\%). ${ }^{72-74}$ Therefore, we should be careful in interpreting the results concerning ESD with noncurative resection for undifferentiated-type EGC. Conversely, studies about gastrectomy as the initial treatment are also affected by selection bias. Thus, it should be noted that these studies also have this limitation.

\section{Risk-scoring system for patients with noncurative resection}

Based on the previous reports, ${ }^{53,54,57-61,63-70}$ LNM was not shown in $89.0 \%$ to $94.8 \%$ of patients who underwent additional surgery after noncurative ER for EGC. Accordingly, additional

Table 4. Risk Factors for LNM on Multivariate Analysis in Patients with Additional Surgery after ESD with Noncurative Resection for EGCs $(\geq 100$ Cases)

\begin{tabular}{|c|c|c|c|c|c|c|}
\hline Author (year) & Country & $\begin{array}{c}\text { No. of } \\
\text { patients }\end{array}$ & Period & $\begin{array}{c}\text { LNM rate, } \\
\%\end{array}$ & Risk factors & OR (95\% CI) \\
\hline \multirow[t]{4}{*}{ Hatta et al. (2017) ${ }^{64}$} & Japan & 1,101 & $00-11$ & 8.5 & Lymphatic invasion & $3.99(2.43-6.55)$ \\
\hline & & & & & Tumor size $>30 \mathrm{~mm}$ & $2.03(1.28-3.14)$ \\
\hline & & & & & Positive VM & $1.81(1.10-3.00)$ \\
\hline & & & & & Vascular invasion & $1.65(1.01-2.70)$ \\
\hline \multirow[t]{2}{*}{ Kim et al. $(2017)^{70}$} & Korea & 350 & $04-14$ & 8.57 & Lymphovascular invasion & $5.619(2.400-13.153)$ \\
\hline & & & & & pT1b(SM2) & $3.224(1.320-7.876)$ \\
\hline \multirow[t]{2}{*}{ Suzuki et al. $(2017)^{57}$} & Japan & 338 & $99-10$ & 5.3 & Positive VM with pT1b(SM2) & $3.6(1.3-10.2)$ \\
\hline & & & & & Lymphovascular invasion & $3.5(1.2-10.4)$ \\
\hline Kawata et al. $(2017)^{58}$ & Japan & 323 & $02-12$ & 9.3 & Lymphovascular invasion & $8.57(2.76-38.14)$ \\
\hline \multirow[t]{2}{*}{ Jung et al. (2017) ${ }^{69}$} & Korea & 321 & $07-15$ & 7.2 & Lymphovascular invasion & $8.701(2.829-26.761)$ \\
\hline & & & & & Positive VM & $3.753(1.431-9.842)$ \\
\hline \multirow[t]{3}{*}{ Sunagawa et al. $(2017)^{66}$} & Japan & 200 & $05-15$ & 7.5 & Lymphatic invasion & $14.2(1.41-16.8)$ \\
\hline & & & & & Macroscopic appearance (flat/elevated) & $4.63(1.04-18.0)$ \\
\hline & & & & & Vascular invasion & $4.00(1.04-18.0)$ \\
\hline \multirow[t]{2}{*}{ Toyokawa et al. $(2016)^{67}$} & Japan & 100 & $04-13$ & 9.0 & Undifferentiated-type & $45.58(2.88-720.94)$ \\
\hline & & & & & Lymphovascular invasion & 38.38 (1.94-761.43) \\
\hline
\end{tabular}

LNM, lymph node metastasis; ESD, endoscopic submucosal dissection; EGCs, early gastric cancers; OR, odds ratio; CI, confidence interval; VM, vertical margin; pT1b(SM2), tumor invasion into the submucosa $\geq 500 \mu \mathrm{m}$ from the muscularis mucosa. 
surgery for all such patients may be excessive and further risk stratification can be useful for deciding treatment strategy after ER

Now, two risk-scoring systems are available. One is the eCura system from Japan (Table 5). ${ }^{64}$ This system was developed from the largest series of EGCs, involving 1,101 patients who underwent additional surgery after noncurative ESD. Based on the risk for LNM, weighted points were assigned for five pathological factors: 3 points for lymphatic invasion and 1 point each for tumor size $>30 \mathrm{~mm}$, positive VM, pT1b(SM2), and vascular invasion. On the other hand, undifferentiated-type and ulceration had 0 points. In this system, total risk scores were categorized as low-risk (0-1 point), intermediate-risk (2-4 points), and highrisk (5-7 points) for LNM. The rates of LNM in each risk category were $2.5 \%, 6.7 \%$, and $22.7 \%$, respectively. Furthermore, when the eCura system was applied to patients with no additional treatment after noncurative ESD, the 5-year DSSs in each risk category were 99.6\%, 96.0\%, and 90.1\%, respectively. In particular, the 5-year DSSs in patients with additional surgery and those with no additional treatment were similar in the lowrisk category (99.7\% vs 99.6\%). ${ }^{75}$ Therefore, follow-up with no additional treatment for patients in the low-risk category of the eCura system may be an acceptable option, especially in some of elderly patients.

Another scoring system is from Korea (Table 6). ${ }^{69}$ This study analyzed 321 patients who underwent additional surgery after noncurative ER, and 2 points were assigned for lymphovascular invasion and 1 point each for female and positive VM. Then, the authors proposed algorism based on their results: 0 points (0\% risk for LNM) for closed follow-up or endoscopic treatment, 1 point (1.9\% risk) for relative indication for additional surgery,

Table 5. Risk-Scoring System (eCura System) Used in Japan for Predicting LNM in Patients with Noncurative Resection after ESD for $\mathrm{EGCs}^{64}$

\begin{tabular}{cclc}
\hline $\begin{array}{c}\text { Total } \\
\text { points* }\end{array}$ & Rate of LNM, \% & Risk category & $\begin{array}{c}\text { Rate of LNM in } \\
\text { risk categories, \% }\end{array}$ \\
\hline 0 & 1.6 & Low-risk & 2.5 \\
1 & 2.6 & Intermediate-risk & 6.7 \\
2 & 4.9 & & \\
3 & 7.4 & High-risk & 22.7 \\
4 & 8.3 & \\
5 & 19.9 & \\
6 & 27.3 & & \\
7 & 26.7 & & \\
\hline
\end{tabular}

LNM, lymph node metastasis; ESD, endoscopic submucosal dissection; EGCs, early gastric cancers; pT1b(SM2), tumor invasion into the submucosa $\geq 500 \mu \mathrm{m}$ from the muscularis mucosa.

*Three points are assigned for lymphatic invasion, 1 point each for tumor size $>30 \mathrm{~mm}$, positive vertical margins, pT1b(SM2), and vascular invasion, and 0 point each for undifferentiated-type and ulceration. and $\geq 2$ points (14.0\% risk) for definite indication of additional surgery.

These risk-scoring systems provide important information for deciding the treatment strategy after noncurative ER. In fact, a recent study confirmed the efficacy of the eCura system for predicting the necessity of additional surgery after noncurative ESD. ${ }^{76}$ However, further external validation is needed in both scoring systems.

\section{Recurrence in patients with no additional treatment after noncurative resection}

When patients select no additional treatment after noncurative ESD despite the guidelines' recommendation for additional surgery, such patients are at risk for recurrence. In the eCura system, the 5-year recurrence rates in the low-, intermediate-, and high-risk categories were $0.7 \%, 5.7 \%$, and $11.7 \%$, respectively ${ }^{64}$ Furthermore, lymphatic invasion was mainly associated with early-phase recurrence, whereas vascular invasion was associated with late-phase recurrence. ${ }^{77}$ This information may help in deciding the treatment strategy in some elderly patients and/ or those with severe underlying diseases. However, it should be noted that, when recurrence is detected in patients who were followed up with no additional treatment after noncurative ESD, most of them have a poor prognosis. ${ }^{78}$

\section{Recurrence in patients with additional surgery after noncurative resection}

Some patients have recurrence even after additional surgery for EGCs with noncurative ESD. In fact, a large-scale study reported that the 5-year DSS in patients who underwent additional surgery after noncurative ESD was 98.7\%.5 Thus, since 1.3\% of patients died of gastric cancer within 5 years even after undergoing additional surgery, it is necessary to identify high-risk patients for recurrence after additional surgery. To date, only one study has focused on this topic. ${ }^{79}$ According to this report, the combination of LNM and vascular invasion led to a highrisk of recurrence. When the status of LNM was subdivided into NO, N1, and N2/N3 according to the 8th edition of the AJCC TNM staging system for gastric cancer, patients with No had little risk for recurrence $(0.3 \%$ to $0.5 \%$ in the 5 -year) regardless of the status of vascular invasion. On the other hand, patients with

Table 6. Risk-Scoring System from Korea Used in Predicting LNM in Patients with Noncurative Resection after ESD for EGC ${ }^{69}$

\begin{tabular}{cc}
\hline Total points* & Rate of LNM, \% \\
\hline 0 & 0.0 \\
1 & 1.9 \\
$\geq 2$ & 14.0 \\
\hline
\end{tabular}

LNM, lymph node metastasis; ESD, endoscopic submucosal dissection; EGCs, early gastric cancers.

*Two points are assigned for lymphovascular invasion, 1 point each for positive vertical margin and female. 
N2/N3 had high-risk for recurrence; 42.9\% in those with positive vascular invasion and $27.3 \%$ in those with negative vascular invasion in the 5-year. In patients with N1, recurrence after additional surgery depended on the status of vascular invasion; $19.4 \%$ in those with positive vascular invasion and $0.0 \%$ in those with negative vascular invasion. Thus, patients with N2/ $\mathrm{N} 3$ and both N1 and vascular invasion may be at high-risk for recurrence after additional surgery. ${ }^{79}$ For such patients, further treatment, such as adjuvant chemotherapy, may be useful (Fig. 2). However, the small number of cases with recurrence after additional surgery is the main limitation of this study. Hence, a further large-scale multicenter study will be needed to resolve this issue in future.

\section{The role of lymphatic and vascular invasion for metastasis after noncurative resection}

Both lymphatic and vascular invasions play an important but different role in metastasis. lymphatic invasion is the highest risk factor for regional LNM in patients with noncurative ESD for EGCs. ${ }^{64}$ Conversely, lymphatic invasion did not affect the recurrence rate after additional gastrectomy with lymph node dissection. ${ }^{79}$ When follow-up without additional surgery was selected after noncurative ESD for EGCs, lymphatic invasion was an independent risk factor for recurrence, mainly as distant metastases. ${ }^{55}$ From these results, EGC with lymphatic invasion might metastasize to distant lymph nodes and/or other organs via regional LNM. Meanwhile, a large-scale study identified vascular invasion as an independent risk factor for regional LNM, although its significance was nearly borderline. ${ }^{64}$ On the other hand, vascular invasion had little risk of recurrence after additional surgery when regional LNM was absent, in contrast to the much higher risk for recurrence under the presence of re- gional LNM. ${ }^{79}$ Although its mechanism is unclear, the presence of cancer cells in veins with the capability of regional LNM may represent their aggressive nature to metastasize to distant lymph nodes and/or other organs.

\section{Management after noncurative resection}

Additional surgery is the standard treatment after noncurative ESD. ${ }^{25,27-30}$ Furthermore, when recurrence is found after selecting no additional treatment in noncurative ESD, most patients cannot achieve long-term survival. ${ }^{78}$ Thus, additional surgery should be selected in healthy, non-elderly patients (Fig. 2). However, in some elderly patients and/or those with severe underlying diseases, the advantages and disadvantages of additional surgery should be considered when selecting the treatment strategy after noncurative ESD. In this regard, risk-scoring systems for LNM may facilitate the clinical decision in patients who underwent noncurative ESD. However, for treatment selection, not only the risk of LNM but also the condition of patients are taken into account. For example, additional surgery is sometimes avoided even in patients with a high-risk for LNM in the scoring system when the risk of surgery is regarded as too high. Furthermore, follow-up with no additional treatment is sometimes selected in patients who are not expected to have long-term survival. Since $H$. pylori prevalence rates are markedly lower in younger people compared to that in older people, ${ }^{6}$ the prevalence of gastric cancer will decrease but patients with gastric cancer will be older. ${ }^{80}$ In elderly patients with gastric cancer, it is necessary to evaluate not only the risk for LNM but also the condition of the patients because heterogeneity in the aging process leads to a diverse range of age-related declines in health and physical status among elderly patients. To date, several indices for evaluating the condition of patients, such as

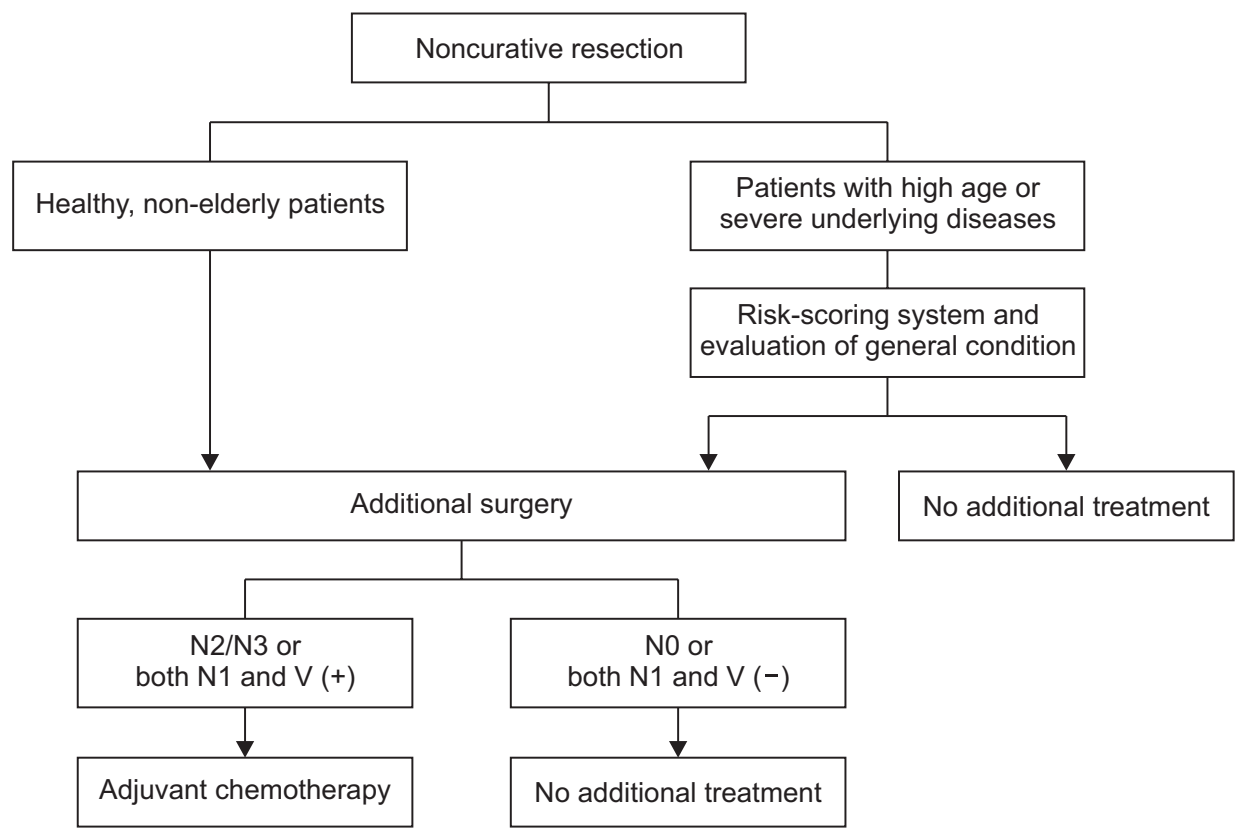

Fig. 2. Proposal of the management strategy for endoscopic submucosal dissection with noncurative resection for early gastric cancers. $\mathrm{V}(+)$, positive vascular invasion; $\mathrm{V}$ $(-)$, negative vascular invasion. 
prognostic nutritional index, ${ }^{81,82}$ Charlson comorbidity index, ${ }^{81,83}$ and American Society of Anesthesiologists' Physical Status, ${ }^{84,85}$ have been reported as indicators for the prognosis in patients with EGCs. However, some reports have shown conflicting results. ${ }^{81,83-86}$ Therefore, for deciding treatment strategy in elderly patients with noncurative resection of ESD for EGCs, the establishment of a reliable tool for predicting the prognosis is demanded.

\section{SUMMARY AND CONCLUSIONS}

In patients with expanded curative resection, the management should differ between Eastern Asian countries and Western countries: the Japanese guidelines can be applied to Eastern Asian countries, but additional surgery may be recommended for patients with undifferentiated-type, ulcerated, or pT1b(SM1) EGCs in Western countries. Among patients with noncurative ESD, additional surgery is recommended for all healthy, nonelderly patients. On the other hand, risk-scoring systems may help in selecting the treatment strategy after noncurative ESD in some elderly patients and/or those with severe underlying disease. In the future, a new tool for evaluating the condition of patients should be established.

\section{CONFLICTS OF INTEREST}

No potential conflict of interest relevant to this article was reported.

\section{AUTHOR CONTRIBUTIONS}

Conception and design: W.H., T.G. Drafting of the article: W.H. Critical revision of the article for important intellectual content: T.G., T.K., A.M. Study supervision: T.G., A.M.

\section{ORCID}

$\begin{array}{ll}\text { Waku Hatta } & \text { https://orcid.org/0000-0001-9717-0281 } \\ \text { Takuji Gotoda } & \text { https://orcid.org/0000-0001-6904-6777 } \\ \text { Tomoyuki Koike } & \text { https://orcid.org/0000-0001-6472-3257 } \\ \text { Atsushi Masamune } & \text { https://orcid.org/0000-0001-7184-7282 }\end{array}$

\section{REFERENCES}

1. Global Burden of Disease Cancer Collaboration, Fitzmaurice C, Dicker D, et al. The Global Burden of Cancer 2013. JAMA Oncol 2015;1:505-527.

2. Karimi P, Islami F, Anandasabapathy S, Freedman ND, Kamangar F. Gastric cancer: descriptive epidemiology, risk factors, screening, and prevention. Cancer Epidemiol Biomarkers Prev 2014;23:700713.

3. de Martel C, Forman D, Plummer M. Gastric cancer: epidemiology and risk factors. Gastroenterol Clin North Am 2013;42:219-240.

4. Suzuki S, Gotoda T, Kusano C, Iwatsuka K, Moriyama M. The efficacy and tolerability of a triple therapy containing a potassiumcompetitive acid blocker compared with a 7-day PPI-based low-dose clarithromycin triple therapy. Am J Gastroenterol 016;111:949-956.

5. Murakami K, Sakurai Y, Shiino M, Funao N, Nishimura A, Asaka M. Vonoprazan, a novel potassium-competitive acid blocker, as a component of first-line and second-line triple therapy for Helicobacter pylori eradication: a phase III, randomised, double-blind study. Gut 2016;65:1439-1446.

6. Kamada T, Haruma K, Ito M, et al. Time trends in Helicobacter pylori infection and atrophic gastritis over 40 years in Japan. Helicobacter 2015;20:192-198.

7. Balakrishnan M, George R, Sharma A, Graham DY. Changing trends in stomach cancer throughout the world. Curr Gastroenterol Rep 2017;19:36.

8. Lee KJ, Inoue M, Otani T, et al. Gastric cancer screening and subsequent risk of gastric cancer: a large-scale population-based cohort study, with a 13-year follow-up in Japan. Int J Cancer 2006;118:2315-2321.

9. Matsumoto S, Yamasaki K, Tsuji K, Shirahama S. Results of mass endoscopic examination for gastric cancer in Kamigoto Hospital, Nagasaki Prefecture. World J Gastroenterol 2007;13:4316-4320.

10. Watabe H, Mitsushima T, Yamaji Y, et al. Predicting the development of gastric cancer from combining Helicobacter pylori antibodies and serum pepsinogen status: a prospective endoscopic cohort study. Gut 2005;54:764-768.

11. Ono H, Kondo H, Gotoda T, et al. Endoscopic mucosal resection for treatment of early gastric cancer. Gut 2001;48:225-229.

12. Japanese Gastric Cancer Association. Japanese classification of gastric carcinoma: 3rd English edition. Gastric Cancer 2011;14:101-112.

13. Suh M, Choi KS, Lee YY, Jun JK. Trends in cancer screening rates among Korean men and women: results from the Korean National Cancer Screening Survey, 2004-2012. Cancer Res Treat 2013;45:86-94.

14. Kim YG, Kong SH, Oh SY, et al. Effects of screening on gastric cancer management: comparative analysis of the results in 2006 and in 2011. J Gastric Cancer 2014;14:129-134.

15. Hirao M, Masuda K, Asanuma T, et al. Endoscopic resection of early gastric cancer and other tumors with local injection of hypertonic saline-epinephrine. Gastrointest Endosc 1988;34:264269.

16. Inoue H, Takeshita K, Hori H, Muraoka Y, Yoneshima H, Endo M. Endoscopic mucosal resection with a cap-fitted panendoscope for esophagus, stomach, and colon mucosal lesions. Gastrointest Endosc 1993;39:58-62.

17. Tada M, Murakami A, Karita M, Yanai H, Okita K. Endoscopic resection of early gastric cancer. Endoscopy 1993;25:445-450.

18. Tanabe S, Koizumi W, Kokutou M, et al. Usefulness of endoscopic aspiration mucosectomy as compared with strip biopsy 
for the treatment of gastric mucosal cancer. Gastrointest Endosc 1999;50:819-822.

19. Ohkuwa M, Hosokawa K, Boku N, Ohtu A, Tajiri H, Yoshida S. New endoscopic treatment for intramucosal gastric tumors using an insulated-tip diathermic knife. Endoscopy 2001;33:221-226.

20. Gotoda T, Kondo H, Ono H, Saito D, Shimoda T. Result of an endoscopic mucosal resection demonstrated at the International Gastric Cancer Congress in New York. Gastric Cancer 2002;5:183184.

21. Miyamoto S, Muto M, Hamamoto Y, et al. A new technique for endoscopic mucosal resection with an insulated-tip electrosurgical knife improves the completeness of resection of intramucosal gastric neoplasms. Gastrointest Endosc 2002;55:576-581.

22. Jang JS, Lee EJ, Lee SW, et al. Endoscopic submucosal dissection for early gastric cancer and gastric adenoma. Korean J Gastroenterol 2007;49:356-363.

23. Chung IK, Lee JH, Lee SH, et al. Therapeutic outcomes in 1000 cases of endoscopic submucosal dissection for early gastric neoplasms: Korean ESD Study Group multicenter study. Gastrointest Endosc 2009;69:1228-1235.

24. Fujishiro M, Yoshida S, Matsuda R, Narita A, Yamashita H, Seto Y. Updated evidence on endoscopic resection of early gastric cancer from Japan. Gastric Cancer 2017;20:39-44.

25. Pimentel-Nunes P, Dinis-Ribeiro M, Ponchon T, et al. Endoscopic submucosal dissection: European Society of Gastrointestinal Endoscopy (ESGE) Guideline. Endoscopy 2015;47:829-854.

26. Gotoda T, Kondo H, Ono H, et al. A new endoscopic mucosal resection procedure using an insulation-tipped electrosurgical knife for rectal flat lesions: report of two cases. Gastrointest Endosc 1999;50:560-563.

27. Ono H, Yao K, Fujishiro M, et al. Guidelines for endoscopic submucosal dissection and endoscopic mucosal resection for early gastric cancer. Dig Endosc 2016;28:3-15.

28. Japanese Gastric Cancer Association. Japanese gastric cancer treatment guidelines 2014 (ver. 4). Gastric Cancer 2017;20:1-19.

29. Guideline Committee of the Korean Gastric Cancer Association (KGCA), Development Working Group \& Review Panel. Korean practice guideline for gastric cancer 2018: an evidence-based, multi-disciplinary approach. J Gastric Cancer 2019;19:1-48.

30. Japanese Gastric Cancer Association. Gastric cancer treatment guideline. 5th ed. Tokyo: Kanehara, 2018.

31. Hasuike N, Ono H, Boku N, et al. A non-randomized confirmatory trial of an expanded indication for endoscopic submucosal dissection for intestinal-type gastric cancer (cT1a): the Japan Clinical Oncology Group study (JCOG0607). Gastric Cancer 2018;21:114123.

32. Jung DH, Bae YS, Yoon SO, et al. Poorly differentiated carcinoma component in submucosal layer should be considered as an additional criterion for curative endoscopic resection of early gastric cancer. Ann Surg Oncol 2015;22:S772-S777.

33. Gotoda T, Yanagisawa A, Sasako M, et al. Incidence of lymph node metastasis from early gastric cancer: estimation with a large number of cases at two large centers. Gastric Cancer 2000;3:219225.

34. Hirasawa T, Gotoda T, Miyata S, et al. Incidence of lymph node metastasis and the feasibility of endoscopic resection for undifferentiated-type early gastric cancer. Gastric Cancer 2009;12:148152.

35. Abdelfatah MM, Barakat M, Lee H, et al. The incidence of lymph node metastasis in early gastric cancer according to the expanded criteria in comparison with the absolute criteria of the Japanese Gastric Cancer Association: a systematic review of the literature and meta-analysis. Gastrointest Endosc 2018;87:338-347.

36. Choi AH, Nelson RA, Merchant SJ, Kim JY, Chao J, Kim J. Rates of lymph node metastasis and survival in T1a gastric adenocarcinoma in Western populations. Gastrointest Endosc 2016;83:11841192.

37. Nam MJ, Oh SJ, Oh CA, et al. Frequency and predictive factors of lymph node metastasis in mucosal cancer. J Gastric Cancer 2010;10:162-167.

38. Fang WL, Huang KH, Lan YT, et al. The risk factors of lymph node metastasis in early gastric cancer. Pathol Oncol Res 2015;21:941946.

39. Hanada Y, Choi AY, Hwang JH, et al. Low frequency of lymph node metastases in patients in the United States with early-stage gastric cancers that fulfill Japanese endoscopic resection criteria. Clin Gastroenterol Hepatol 2019;17:1763-1769.

40. Abdelfatah MM, Barakat M, Othman MO, Grimm IS, Uedo N. The incidence of lymph node metastasis in submucosal early gastric cancer according to the expanded criteria: a systematic review. Surg Endosc 2019;33:26-32.

41. Isomoto H, Shikuwa S, Yamaguchi N, et al. Endoscopic submucosal dissection for early gastric cancer: a large-scale feasibility study. Gut 2009;58:331-336.

42. Gotoda T, Iwasaki M, Kusano C, Seewald S, Oda I. Endoscopic resection of early gastric cancer treated by guideline and expanded National Cancer Centre criteria. Br J Surg 2010;97:868-871.

43. Okada K, Fujisaki J, Yoshida T, et al. Long-term outcomes of endoscopic submucosal dissection for undifferentiated-type early gastric cancer. Endoscopy 2012;44:122-127.

44. Toyonaga T, Man-i M, East JE, et al. 1,635 Endoscopic submucosal dissection cases in the esophagus, stomach, and colorectum: complication rates and long-term outcomes. Surg Endosc 2013;27:1000-1008.

45. Choi MK, Kim GH, Park DY, et al. Long-term outcomes of endoscopic submucosal dissection for early gastric cancer: a singlecenter experience. Surg Endosc 2013;27:4250-4258.

46. Shin KY, Jeon SW, Cho KB, et al. Clinical outcomes of the endoscopic submucosal dissection of early gastric cancer are comparable between absolute and new expanded criteria. Gut Liver 2015;9:181-187.

47. Kosaka T, Endo M, Toya Y, et al. Long-term outcomes of endoscopic submucosal dissection for early gastric cancer: a singlecenter retrospective study. Dig Endosc 2014;26:183-191. 
48. Kim SG, Park CM, Lee NR, et al. Long-term clinical outcomes of endoscopic submucosal dissection in patients with early gastric cancer: a prospective multicenter cohort study. Gut Liver 2018;12:402-410.

49. Takizawa K, Ono H, Hasuike N, et al. A non-randomized singlearm confirmatory trial of endoscopic submucosal dissection to expand its indication for early gastric cancer of undifferentiated type: Japan Clinical Oncology Group Study (JCOG1009/1010). Gastrointest Endosc 2019;89: AB347-AB348.

50. Tanabe S, Ishido K, Matsumoto T, et al. Long-term outcomes of endoscopic submucosal dissection for early gastric cancer: a multicenter collaborative study. Gastric Cancer 2017;20:45-52.

51. Lee S, Choi KD, Hong SM, et al. Pattern of extragastric recurrence and the role of abdominal computed tomography in surveillance after endoscopic resection of early gastric cancer: Korean experiences. Gastric Cancer 2017;20:843-852.

52. Min BH, Kim ER, Kim KM, et al. Surveillance strategy based on the incidence and patterns of recurrence after curative endoscopic submucosal dissection for early gastric cancer. Endoscopy 2015;47:784-793.

53. Probst A, Schneider A, Schaller T, Anthuber M, Ebigbo A, Messmann H. Endoscopic submucosal dissection for early gastric cancer: are expanded resection criteria safe for Western patients? Endoscopy 2017;49:855-865.

54. Suzuki H, Takizawa K, Hirasawa T, et al. Short-term outcomes of multicenter prospective cohort study of gastric endoscopic resection: 'Real-world evidence' in Japan. Dig Endosc 2019;31:30-39.

55. Hatta W, Gotoda T, Oyama T, et al. Is radical surgery necessary in all patients who do not meet the curative criteria for endoscopic submucosal dissection in early gastric cancer? A multi-center retrospective study in Japan. J Gastroenterol 2017;52:175-184.

56. Yang HJ, Kim SG, Lim JH, et al. Predictors of lymph node metastasis in patients with non-curative endoscopic resection of early gastric cancer. Surg Endosc 2015;29:1145-1155.

57. Suzuki H, Oda I, Abe S, et al. Clinical outcomes of early gastric cancer patients after noncurative endoscopic submucosal dissection in a large consecutive patient series. Gastric Cancer 2017;20:679-689.

58. Kawata N, Kakushima N, Takizawa K, et al. Risk factors for lymph node metastasis and long-term outcomes of patients with early gastric cancer after non-curative endoscopic submucosal dissection. Surg Endosc 2017;31:1607-1616.

59. Kikuchi S, Kuroda S, Nishizaki M, et al. Management of early gastric cancer that meet the indication for radical lymph node dissection following endoscopic resection: a retrospective cohort analysis. BMC Surg 2017;17:72.

60. Kim ER, Lee H, Min BH, et al. Effect of rescue surgery after noncurative endoscopic resection of early gastric cancer. Br J Surg 2015;102:1394-1401.

61. Yano T, Ishido K, Tanabe S, et al. Long-term outcomes of patients with early gastric cancer found to have lesions for which endoscopic treatment is not indicated on histopathological evaluation after endoscopic submucosal dissection. Surg Endosc 2018;32:1314-1323.

62. Suzuki S, Gotoda T, Hatta W, et al. Survival benefit of additional surgery after non-curative endoscopic submucosal dissection for early gastric cancer: a propensity score matching analysis. Ann Surg Oncol 2017;24:3353-3360.

63. Ito H, Inoue H, Ikeda H, et al. Surgical outcomes and clinicopathological characteristics of patients who underwent potentially noncurative endoscopic resection for gastric cancer: a report of a single-center experience. Gastroenterol Res Pract 2013;2013:427405.

64. Hatta W, Gotoda T, Oyama T, et al. A scoring system to stratify curability after endoscopic submucosal dissection for early gastric cancer: "eCura system". Am J Gastroenterol 2017;112:874-881.

65. Hoteya S, Iizuka T, Kikuchi D, et al. Clinicopathological outcomes of patients with early gastric cancer after non-curative endoscopic submucosal dissection. Digestion 2016;93:53-58.

66. Sunagawa H, Kinoshita T, Kaito A, et al. Additional surgery for non-curative resection after endoscopic submucosal dissection for gastric cancer: a retrospective analysis of 200 cases. Surg Today 2017;47:202-209.

67. Toyokawa T, Ohira M, Tanaka H, et al. Optimal management for patients not meeting the inclusion criteria after endoscopic submucosal dissection for gastric cancer. Surg Endosc 2016;30:24042414

68. Yamanouchi K, Ogata S, Sakata Y, et al. Effect of additional surgery after noncurative endoscopic submucosal dissection for early gastric cancer. Endosc Int Open 2016;4:E24-E29.

69. Jung DH, Huh CW, Kim JH, et al. Risk-stratification model based on lymph node metastasis after noncurative endoscopic resection for early gastric cancer. Ann Surg Oncol 2017;24:1643-1649.

70. Kim HS, Ahn JY, Kim SO, Kim BS. Can further gastrectomy be avoided in patients with incomplete endoscopic resection? Surg Endosc 2017;31:4735-4748.

71. Miyahara K, Hatta W, Nakagawa M, et al. The role of an undifferentiated component in submucosal invasion and submucosal invasion depth after endoscopic submucosal dissection for early gastric cancer. Digestion 2018;98:161-168.

72. Youn HG, An JY, Choi MG, Noh JH, Sohn TS, Kim S. Recurrence after curative resection of early gastric cancer. Ann Surg Onco 2010;17:448-454.

73. Sano T, Sasako M, Kinoshita T, Maruyama K. Recurrence of early gastric cancer. Follow-up of 1475 patients and review of the Japanese literature. Cancer 1993;72:3174-3178.

74. Ikeda Y, Saku M, Kishihara F, Maehara Y. Effective follow-up for recurrence or a second primary cancer in patients with early gastric cancer. Br J Surg 2005;92:235-239.

75. Hatta W, Gotoda T, Oyama T, et al. Is the eCura system useful for selecting patients who require radical surgery after noncurative endoscopic submucosal dissection for early gastric cancer? A comparative study. Gastric Cancer 2018;21:481-489.

76. Niwa H, Ozawa R, Kurahashi Y, et al. The eCura system as a novel indicator for the necessity of salvage surgery after non- 
curative ESD for gastric cancer: a case-control study. PLoS One 2018;13:e0204039.

77. Yamada S, Hatta W, Shimosegawa T, et al. Different risk factors between early and late cancer recurrences in patients without additional surgery after noncurative endoscopic submucosal dissection for early gastric cancer. Gastrointest Endosc 2019;89:950960.

78. Takizawa K, Hatta W, Gotoda T, et al. Recurrence patterns and outcomes of salvage surgery in cases of non-curative endoscopic submucosal dissection without additional radical surgery for early gastric cancer. Digestion 2019;99:52-58.

79. Hatta W, Gotoda T, Oyama T, et al. Is additional surgery always sufficient for preventing recurrence after endoscopic submucosal dissection with curability C-2 for early gastric cancer? Ann Surg Oncol 2019;26:3636-3643.

80. Mizota Y, Yamamoto S. How long should we continue gastric cancer screening? From an epidemiological point of view. Gastric Cancer 2019;22:456-462.

81. Iwai N, Dohi 0, Naito Y, et al. Impact of the Charlson comorbidity index and prognostic nutritional index on prognosis in patients with early gastric cancer after endoscopic submucosal dissection.
Dig Endosc 2018;30:616-623.

82. Sekiguchi M, Oda I, Suzuki H, et al. Clinical outcomes and prognostic factors in gastric cancer patients aged $\geq 85$ years undergoing endoscopic submucosal dissection. Gastrointest Endosc 2017;85:963-972.

83. Toya Y, Endo M, Nakamura S, et al. Long-term outcomes and prognostic factors with non-curative endoscopic submucosal dissection for gastric cancer in elderly patients aged $\geq 75$ years. Gastric Cancer 2019;22:838-844.

84. Yoshifuku Y, Oka S, Tanaka S, et al. Long-term prognosis after endoscopic submucosal dissection for early gastric cancer in super-elderly patients. Surg Endosc 2016;30:4321-4329.

85. Tanoue K, Fukunaga S, Nagami Y, et al. Long-term outcome of endoscopic submucosal dissection for early gastric cancer in patients with severe comorbidities: a comparative propensity score analysis. Gastric Cancer 2019;22:558-566.

86. Kusano C, Iwasaki M, Kaltenbach T, Conlin A, Oda I, Gotoda T. Should elderly patients undergo additional surgery after noncurative endoscopic resection for early gastric cancer? Long-term comparative outcomes. Am J Gastroenterol 2011;106:1064-1069. 